\title{
El lugar como dispositivo estético: flujos, pasajes y recorridos de la experiencia urbana
}

\author{
Esteban Marcos Dipaola \\ Doctor en Ciencias Sociales (Universidad de Buenos Aires); \\ Profesor auxiliar de la Universidad de Buenos Aires. \\ Buenos Aires, Argentina \\ estabandip@yahoo.com.ar
}

\begin{abstract}
Resumen El artículo se centra en el análisis de la categoría de lugar en relación con lo urbano y sus prácticas en la postmodernidad. Asume un criterio de análisis metodológico sostenido en la perspectiva hermenéutica que pretende definir el lugar y lo urbano como producción de sentidos y flujos. Entonces, se define el lugar como dispositivo estético $\mathrm{y}$, a partir de ello, se establecen las dimensiones de la experiencia, de los pasajes y de la visualidad como expresiones singulares que definen el lugar sin atribuirle una representación definida. En primer término, se cuestiona la idea de representación y la definición de lugar según sus límites. Enseguida, se propone el pensamiento estético del lugar como expresión. Finalmente, se detalla lo que se comprende como visualidad del lugar. Entre estas relaciones conceptuales se evidencia una crítica a la categoría de "no lugar" y se consideran los flujos y tránsitos que permiten pensar los lugares.
\end{abstract}

Palabras clave: lugar, espacio urbano, flujos, pasajes, estética.

\section{Introducción}

T a pregunta por el lugar en los tiempos actuales se inscribe en sí misL ma como pregunta metodológica, y expone un criterio metodológico particular: es una pregunta hermenéutica. En primera instancia, la interrogación por el lugar refiere a un criterio espacial o territorial, a una situación y ubicación que determine coordenadas específicas. Sin embargo, si exigimos una problematización algo más profunda, encontraremos que la dimensión del lugar reclama instancias de expresión más amplias y diseminadas. Abrir el lugar a sus problemáticas, a su multidimensionalidad concreta la experiencia de ciertas posibilidades interpretativas. El lugar como premisa de interpretaciones, es decir, una concepción del espacio que se presente como potencia de lectura de las prácticas cotidianas que los diferentes individuos realizan sobre el mismo.

El lugar como práctica hermenéutica es entonces un ejercicio de pensamiento de los trayectos, de las bifurcaciones, de los pasajes, de las imágenes que lo representan, de las escrituras que lo definen y describen. El lugar es la transposición de múltiples recorridos. De acuerdo con tales condiciones, el lugar puede definirse como una estética.

La propuesta principal y guía de este artículo es, precisamente, pensar la emergencia de una experiencia del lugar como dispositivo estético. Esto implica anticipar que el lugar es por sí mismo una esté- 
tica, lo cual significa una experiencia artística, pero también una praxis. Además, indica proponer la idea de lugar en los tiempos de la postmodernidad y la globalización en sociedades mediatizadas, es decir, una condición de lugar y de espacio que no se define por sus límites, sus fronteras, sus determinaciones geográficas, sino que es expresión de recorridos, de objetos, de mercancías, de prácticas y relaciones sociales, de experiencias cotidianas de los individuos que los transitan, de formas de consumos y de condiciones de representación. Sobre estas condiciones que evidencian una correspondencia entre un proceso de reestructuración económica y un modo específico de desarrollo informacional propio de la globalización surge, tal como lo define García Vázquez (2008, p. 57), "una nueva espacialidad que se ha dado en llamar 'el espacio de los flujos'. Es decir, un sistema integrado de producción y consumo, fuerza de trabajo y capital, cuya base son las redes de información".

$\mathrm{Si}$ es necesario atender a las condiciones del lugar como espacio de flujos, deben considerarse la transitoriedad, la ocasionalidad, el azar y derivas no definibles a priori que organizan novedosos interrogantes que tienden a dar cuenta de las normativas que conforman experiencias del lugar. De este modo, la hermenéutica del lugar obtiene su definición de esas múltiples aperturas de las preguntas y problematizaciones sobre la experiencia que hacemos entre los lugares.

\section{El lugar como representación}

La posición que define al lugar por sus determinaciones físicas, esto es, por sus precisiones respecto a los límites que lo circundan, conserva una predominancia representativa que fija el lugar en un supuesto espacial desatendiendo dimensiones necesarias -con más razón en los tiempos corrientes- respecto a otro tipo de variables que conforman la experiencia del lugar. Esa es la clave interpretativa necesaria para el análisis y el abordaje de las experiencias que componen los lugares.

El lugar como representación es quizás una imagen fija que posibilita en un inicio establecer una primera relación con el lugar. El arribo a una ciudad desconocida requiere la apreciación de límites, de ubicación de un centro, de formas geográficas que indiquen una primera aproximación a las posibilidades de circulación que en el lugar se perciben como existentes o posibles. Esta primera instancia, que podemos llamar cartográfica, precisamente, nos sitúa en el mapa que organiza en los individuos una inicial representación del lugar o de la ciudad que se empieza a conocer. Sin embargo, prontamente y a medida que cada individuo se familiariza con los espacios que instituyen la apreciación del lugar o de la ciudad, aquellas formas de circulación comenzarán a confluir con nuevos recorridos, con bifurcaciones $\mathrm{y}$ trayectos distintos, con espacios diferentes de intervención, con prácticas y relaciones con otros que también transitan esos espacios. De esta manera, las formas de circulación por los lugares comenzarán a variar, a diversificarse, a trasponerse, de tal modo que la propia experiencia que cada individuo realice del espacio se transformará y los límites que en una primera instancia definían una representación específica del lugar serán transformados, vueltos a explorar y, en definitiva, vueltos a ser creados. Por eso, todo lugar es una experiencia móvil que exige otras instancias diferentes a la representativa para definirse.

Es posible pensar el lugar ya no como una ciudad particular, sino un espacio de compras, de tránsito, de ocio, etc. Si, por ejemplo, pensamos en un shopping, dentro de sus singulares características, las formas de concretar una experiencia de y sobre el mismo pueden analizarse como similares a las que referíamos asumiendo en un sentido más general una definición de lugar como ciudad. Si se ingresa a un centro de compras por primera vez, el recorrido tiende a ser circular, esto por la propia disposición general y visual de tales lugares, así como por la propia experiencia individual que permite localizarse mejor asumiendo la linealidad del trayecto. Esa racionalidad organizativa del shopping es definida por Sarlo de la siguiente manera:

El shopping es un espacio de conexiones cuyos elementos "gramaticales" deben mantener una relación ordenada para ser comprensibles y son comprensibles porque la mantienen. [...] El shopping es ordenado porque expulsa la idea misma de desorden y se opone así a la ciudad, cuyo espacio público, incluso en sus momentos y lugares de mayor ordenamiento, no puede condenar de manera instantánea el uso no previsto[...] En el registro visual, el shopping comunica lo que organiza en el registro práctico. (Sarlo, 2009, p. 21-22 y 24-25)

Ahora bien, cuando ya se tiene un conocimiento mayor del espacio y de la específica organización del shopping, las formas de circulación se modifican y también comienza a comprobarse la manera en que la disposición de los objetos, de las mercancías alteran la relación de cada individuo con sus tránsitos sobre ese espacio recorrido; entonces el lugar pierde una representación concreta de sus límites, debido a que estos se diseminan en las propias movilidades y experiencias que sobre tales espacios se realizan. Incluso debe decirse que se fractura el propio límite entre el adentro y el afuera. La salida a la calle produce 
la referencia de permanencia relacional con el lugar experimentado anteriormente, pues si una persona se retira de un centro de compras, inmediatamente se encuentra con vendedores callejeros o ambulantes que ofrecen otros productos a menor precio y según otras condiciones. ${ }^{1}$ Esto también conforma parte de la experiencia que realizamos con los lugares y que expresan la imagen que construimos de los mismos.

Otro lugar que puede ser mencionado a modo de ejemplo para seguir evaluando esto que aquí se propone son los aeropuertos. En tales sitios es clara la manera en que los recorridos y las distintas formas de transitar y relacionarse e interactuar con las distintas locaciones determinan experiencias múltiples sobre las percepciones del lugar. Es posible considerar los aeropuertos como ejercicios concretos de concepción de los lugares como estéticas, pues éstos presentan una organización que en sí misma es difusa debido a que obligan a organizar el tiempo de acuerdo con otras modalidades: las esperas, las demoras, los transbordos, las maneras de organizar y leer los arribos y llegadas concretan relaciones y experiencias con el espacio y con el acoplamiento que las personas hacen en él, lo cual exige toda una modalidad hermenéutica de inscripción de esa experiencia.

Debe notarse hasta aquí que la propuesta es suscribir a una noción que identifique los lugares como experiencias de los tránsitos y prácticas en estos realizados, y no asumirlos según una representación definida en sus límites, fronteras y cartografías fijas. La condición de la movilidad posibilita pensar e interpretar los lugares en su permanente vinculación con todo aquello que induce a conformarlo como tal: prácticas de consumos, objetos, mercancías, relaciones humanas, formas y artefactos de comunicación, etc. Eso también abre una nueva manera de mostrar la relación establecida entre el espacio y la temporalidad. Pero también parece necesario evidenciar algo que consideramos esencial para proseguir con el análisis teórico propuesto: me refiero a la insistencia en sostener un discurso y enfoque que persista en la dimensión analítica del "lugar", y diferenciarnos, de este modo, de la prerrogativa surgida a partir de Augé (2007) respecto a los "no lugares".

Según el antropólogo de origen francés:

Los no lugares son tanto las instalaciones necesarias para la circulación acelerada de personas y bienes (vías rápidas, empalmes de rutas, aeropuertos) como los medios de transporte mismos o los grandes centros comerciales, o también los campos de tránsito prolongado donde se estacionan los refugiados del planeta. (AUGÉ, 2007, p. 41)
En articulación con tal definición, Augé (2007) entiende la idea de "sobremodernidad" caracterizada por la condición del exceso, por lo cual esgrime que la producción individual de sentido se vuelve cada vez más necesaria.

De nuestra parte, asentimos con entender lo que aquí denominamos postmodernidad como estando bajo la característica del exceso, sin embargo, no parece estrictamente adecuado pretender la sustancialización de la categoría de "individuo" como emergente de los tiempos corrientes. Precisamente, la definición de "no lugar" que arriesga Augé (2007) solo puede relacionarse con esa tendencia al individualismo que adjudica a las sociedades contemporáneas. En otras palabras, al identificar el autor los tránsitos permanentes como condiciones propias del anonimato, está pretendiendo una oposición analítica con un lugar sustancial y fijo, que puede obtener su definición por sus límites, su organización del saber y por el tejido de un lazo. Pero el hecho de que los tránsitos se vuelvan perpetuos y modifiquen constantemente los límites y fronteras y, con ello, también las relaciones, no implica, con necesidad, la dimensión del individualismo y el anonimato, así como tampoco la resolución de un lazo fragmentado o fracturado que imposibilitaría el ejercicio de relaciones. El lugar, en todo caso, se vuelve una práctica de relaciones más efímeras y flexibles si se quiere, pero que no dejan de ser vínculos. En síntesis, como venimos argumentando, el lugar, dentro de sus movilidades y bifurcaciones, se concreta como experiencia. No se trata ya del no lugar, sino de los tránsitos y relaciones que expresan y componen una experiencia permanentemente móvil de los lugares.

\section{La expresión del lugar: una tesis sobre los pasajes}

En el contexto presente, el espacio se constituye en sus alteraciones, se organiza mediante diseminaciones y flujos. Se trata siempre del espacio de los flujos y la movilidad. De este modo, un lugar como la ciudad se teje entre tránsitos, vivencias, prácticas cotidianas, eventos, fiestas, celebraciones, etc. Se conforma una estética del espacio que puede ser definida a partir del carácter de "pasajes". De acuerdo con Comolli (2007, p. 505) - que sigue la indicación de Benjamin - "la figura del pasaje es la metáfora principal de la ciudad: pasaje de hombres, pasaje de mercaderías, pasaje de deseos, pasaje del tiempo. La

1. Esto ocurre en cualquier shopping de la ciudad de Buenos Aires, en Argentina y en la mayoría de las megalópolis de América Latina. 
ciudad es como un tamiz que retendría algunas trazas de esos pasajes del tiempo".

Los pasajes tienen que ver con apropiaciones, y la ciudad contemporánea se caracteriza en gran manera por la experiencia de la apropiación. La apropiación/ pasaje se relaciona con los usos del espacio que otorgan significados: la realización de un evento artístico en lugares públicos, la ubicación de puestos de venta ambulantes, el establecimiento de "zonas rojas" en determinados y circunscriptos lugares o barrios de una ciudad, las protestas o marchas de trabajadores, movimientos sociales, etc., todo ello atestigua una cierta apropiación del espacio público que organiza una modalidad de pasaje, entendiendo por esto último un tipo de organización del lugar estrictamente pasajera y concerniente únicamente al acontecimiento que la define. Entonces la apropiación/pasaje como estética del espacio configura la diversidad de significados que los lugares adquieren de acuerdo a sus usos. Tales usos, en fin, son formas de tránsitos, apertura de trayectos y una perpetua difusión de los límites posibles. El lugar se vuelve experiencia de sentido, pero solo pasible de ejercicio efectivo en su pasaje grupal o comunitario. Sintéticamente, el lugar se define por sus flujos, sus derivas, sus posibilidades múltiples de caracterizarse o definirse e involucrar en un lazo a los individuos.

En este marco, es necesario afirmar que la postmodernidad ha disuelto la noción que figuraba la ciudad como un "texto" (Barthes, 1957). Cuando anteriormente nos posicionamos metodológicamente para definir la ciudad como hermenéutica e interpretación, no teníamos interés en insistir en esa valiosa noción de texto, sino aplicar la valoración interpretativa a los múltiples significados que un texto adquiere y a las marcas que "deconstruyen" la propia experiencia del texto.

Desde mediados de la década del 2000, surgió desde Barcelona, y continúa actualmente en sus derivas itinerantes por distintas ciudades del mundo, un proyecto estético-urbano denominado "Post-it City". De acuerdo con esa concepción, se procura comprender los significados y despliegues del espacio urbano como articulación de lugares ocasionales. Las ciudades postmodernas organizan sus lugares, ya no de manera uniforme sino por relaciones, vínculos efímeros, experiencias compartidas que se diluyen prontamente, etc. Entonces, el concepto de "Post-it City" "designa distintas ocupaciones temporales del espacio público, ya sean de carácter comercial, lúdico, sexual o de cualquier otra índole, con la característica común de apenas dejar rastro y de autogestionar sus apariciones y desapariciones". ${ }^{3}$ De esta manera, ya no se concibe la posibilidad de un pensamiento que se centre en una supuesta homogeneidad del espacio público, sino que se elabora una concepción que resalte la creatividad en los usos de los lugares, los afectos y determinaciones colectivas que expresan tales espacios, y se descarta que deba existir un consenso acerca del uso de la ciudad y sus lugares, para situarse en la problematización de los diferentes usos y las prácticas, las apropiaciones distintas que un mismo lugar puede tener a partir de la circulación que en el mismo realizan diferentes grupos o comunidades.

Se hace notoria la influencia decisiva de la idea de temporalidad para este tipo de caracterización de los lugares, así como los cambios que recibe la relación entre espacio y tiempo. Puede decirse que el espacio se convierte también en una forma de devenir $\mathrm{y}$, en ese sentido, se inscribe bajo las condiciones de percibirse este mismo como temporalidad. Lo principal es comprender el espacio, las ciudades, los lugares como relaciones, pues si se atiende a ello, se vislumbra que la cualidad de la alteración permanente es lo que define su concepción. Si el espacio urbano, si diferentes lugares son evaluados, no como formas físicas o geográficas rígidas, sino como experiencias culturales, se comprende que estas siempre se encuentran compuestas de afectos, lazos colectivos, emociones, conflictos, etc., y que, precisamente por ello mismo, asisten a una transformación constante de su realidad.

La noción emergente a partir del proyecto "Postit city", entonces, quiebra la necesidad de totalidad a que obliga la más clásica noción de "texto" para situar los significados y signos de una ciudad, y se esfuerza por generar pasajes interpretativos que atiendan a los usos ocasionales de los lugares, a los vínculos y prácticas cotidianas, incluso, a lo fortuito. La insistencia en los pasajes indica interpretar las marcas, las alteraciones, las notas que transforman el texto, y no ceder ante la homogeneidad de inscribir el texto/ciudad como un todo sin desvíos, sin trayectos, sin usos diferenciados.

Así es como puede empezar a desarrollarse una tesis que aborde las consideraciones estéticas en los usos de los lugares. Observar y analizar las apropiaciones y, con ello, los recorridos, las bifurcaciones de distintos trayectos y la organización de variadas prácticas. También las modalidades con que las imágenes habitan las ciudades y sus espacios: los carteles $\mathrm{o}$ afiches publicitarios, las señales de tránsito, la arquitectura, los grafitis, las pantallas gigantes en grandes avenidas configuran modos de visualización y apropiación del espacio urbano. Igualmente, en películas

2. En la Ciudad Autónoma de Buenos Aires, en Argentina, hay determinados espacios públicos denominados "zonas rojas" que se caracterizan por la oferta de "servicios sexuales" en horarios nocturnos.

3. Definición tomada del catálogo de la muestra "Post-it City", realizada en la Ciudad de Buenos Aires durante el mes de agosto del año 2010. 
cinematográficas donde aparecen las calles y los lugares de la ciudad, se desprende una visión característica de esa expresión del espacio urbano. Del mismo modo, ocurre en descripciones de la literatura donde aparecen determinadas calles y sitios característicos, recorridos y distintas formas de realizarlos, aludiendo, justamente, a que los propios trayectos configuran estéticas espaciales.

Eso que definimos como la expresión del lugar refiere, entonces, a aquellas producciones estéticas, a los usos, a las plurales formas de visualización y de recorrido que se corresponden con un exceso en la representación. Esto es, se hace imposible representar el lugar porque este aparece difuso, permanentemente móvil. El lugar se convierte en performativo, es decir, se constituye en la propia experiencia, en el mismo acto de su recorrido y apropiación, y en ese aspecto, es expresivo, expresa sus ocasionales significados mostrando el síntoma de su imposible representación.

En síntesis, la expresión se contrapone a la representación porque si esta última fija y delimita una concepción homogénea y rígida o estandarizada del lugar, contrariamente, la expresión indica su multiplicidad de significados, sus pasajes, su fluidez, su dispersión y despliegue.

\section{El lugar visual: imágenes y flujos de la experiencia urbana}

La conformación del espacio, de los lugares tiene también una estricta relación con las imágenes, lo que deriva en una estetización de los lugares y en una estetización de las relaciones y de los cuerpos involucrados. Así, "el espacio social está hoy completamente saturado con la cultura de la imagen" (Jameson, 2002, p. 150).

Esa experiencia estética sobre la que se configura la normatividad práctica del lugar determina a su vez el establecimiento de un vínculo con las subjetividades que se disponen corporalmente sobre el mismo. De tal manera, subjetividad y lugar son ejercicios de visualidad y se expresan como imágenes.

Esa profunda relación entre los lugares y las subjetividades como imágenes pone también en crisis la propia concepción del lugar, cuestionándose la pertinencia de una realidad del lugar. Como asegura Belting (2007), "los reemplazamos con imágenes de lugares que captamos en las pantallas". Y sigue:

conocemos muchos lugares solamente en imagen. [...] Con esto ocurre un desplazamiento en la relación entre imagen y lugar. En vez de visitar las imágenes en lugares determinados, en la actualidad preferimos visitar los lugares en imagen. (Belting, 2007, p. 77)

Así, el lugar se concibe como una aparición que se constituye en la transitoriedad y en la transición. La transitoriedad en tanto no hay permanencia, y la transición en tanto se circula de una aparición a la otra, pues "también las imágenes pierden el lugar en el que se las podría esperar y en el que comprobaban su presencia" (2007, p. 78).

Pero si permanentemente argumentamos aludiendo a nociones como transitoriedad, transición, ocasionalidad, flujo, etc., retomando discusiones de párrafos anteriores, ¿no estamos admitiendo, en cierto modo, la existencia de los "no lugares" que definía Augé? (2007).

La "contractualidad solitaria" que considera Augé en su argumento desatiende el campo de las prácticas entre individuos, el cual organiza normatividades que no se sostienen en un lazo de sociabilidad trascendente o exterior, sino que se expresan de manera inmanente sobre el propio lugar configurando su experiencia. De esta forma, el lugar organiza su regulación en la propia instancia de participación y acción por parte de los individuos, y no ocurre de manera inversa, como sí tiende a deducirse de una propuesta teórica como la de Augé (2007). Según el antropólogo: "En la situación de supermodernidad, una parte de ese exterior está constituida por no lugares, y una parte de los no lugares, por imágenes" (2007, p. 120). Sin embargo, la producción del espacio en la postmodernidad como transitoriedad y circulación determina una experiencia novedosa en la condición del individuo, pero no implica el absoluto anonimato y la completa fragmentación, ni la solitaria exposición de ese individuo a una experiencia $\sin$ otros. ${ }^{4}$

La ciudad y su práctica acaba siendo una ciudad vivida, y el espacio urbano del siglo XXI se aprecia y define por sus expresiones estéticas, las cuales es posible sintetizar en dos dimensiones generales. Por un lado, la estética en su definición más natural, es decir, como ámbito de la sensibilidad y la experiencia. Por otro lado, la estética como producción artística. En esta línea, se observa que la ciudad se vive en las propias experiencias sensibles de los cuerpos y las subjetividades, en la instancia práctica donde se constituyen los lazos y las sociabilidades. La ciudad y los lugares son constitución normativa en ese campo. Al mismo tiempo, la ciudad y los lugares se definen como obra artística en las derivas de las experiencias de sus circulaciones, trayectos, bifurcaciones, pasajes.

Estas dimensiones de la ciudad como experiencia sensible y de la ciudad como obra de arte gestan una 
experiencia estética del espacio y desprenden las formas visuales que en sus usos y apropiaciones tal espacio contiene y proyecta. La visualización del espacio y de los lugares no corresponde a una visión de algo dado o definido centralmente, sino que es el registro de visualidades que no cesan de fluir, dispersarse e intercambiarse, componiendo una mirada siempre diferente relativa al lugar.

En tiempos actuales de la dinámica global, todo circula, todo deviene y se transforma, y los lugares se atraviesan y experimentan en el marco de una temporalidad en movimiento, generando la emergencia de lazos móviles, flujos que van materializando lugares que, finalmente, no son otra cosa más que experiencias.

Entonces, en las condiciones de la postmodernidad, asistimos al devenir de los flujos, pero como retórica de los lugares. Mongin lo llama la época de las "posciudades", la cual nos introduce en una dimensión "posurbana" y que tuvo su carta de aparición con "la tercera mundialización". Así, la posciudad sería una:

etapa en la que entidades ayer circunscriptas en lugares autónomos, ahora dependen de factores exógenos, principalmente, los flujos tecnológicos, las telecomunicaciones y los transportes... El equilibrio ideal entre los lugares y los flujos se ha vuelto completamente ilusorio. (Mongin, 2006, p. 16)

En este sentido, "el devenir de lo urbano hoy se conjuga en el modo de lo posurbano" (2006, p. 18). Por ello, ya no se puede ceder a la tentación de la "ciudad museo", es decir, sostenida en valores de planificación del espacio tradicionales. "El espacio ciudadano de ayer $[\ldots]$ pierde terreno a favor de una metropolización que es un factor de dispersión, de fragmentación y de multipolarización” (2006, p. 19). A lo largo del siglo XX se ha transitado de la ciudad hacia lo urbano.

Mongin (2006), entonces, propone comprender dos "condiciones urbanas" que dan lugar a las experiencias de lo urbano: por un lado, "la ciudad" que establece límites precisos entre el adentro y el afuera y, por otro lado, lo "urbano generalizado" que es propio de la posciudad, en donde ya no hay límites y se constituye a escala mundial en tendencia con el proceso de "mundialización"; se trata de las "megalópolis", "metrópolis", etc. ${ }^{5}$. La posciudad aparece como lo singular de nuestra experiencia actual, donde los espacios se determinan a partir de los "flujos" y las "redes". ${ }^{6}$ Así, la ciudad actual es una "ciudad de múltiples velocidades" (Mongin, 2006, p. 24), pero: "la potencia de los flujos no impide que aún puedan darse las prácticas urbanas, aun cuando se fragilicen. [...] un lugar urbano es un vector y un permutador de flujo, es decir, un espacio que hace posible interacciones" (2006, p. 142-143).

Entonces, el devenir y la circulación, los "flujos" indefinidos no forman parte de una ruptura de los lazos sociales, sino de series de experiencias de vida en las ciudades, nuevas formas de emprender y comprender la dinámica de esos lazos de interacción. También el lugar se vuelve perspectiva hermenéutica porque ese devenir de los flujos permite considerar el surgimiento de las posciudades y de lo posurbano. En fin, no es que la experiencia urbana ya no sea posible, sino que se vive e interpreta de manera diferente.

Ahora bien, perdida la experiencia de lo urbano según límites, que posibilitaba una visibilidad de prácticas que consolidaban una organización social estable: ¿cómo es que las experiencias propias de las posciudades no nos arrojan al desierto de la individualidad y el puro anonimato? ¿Cómo es que en las posciudades los flujos conformarían lugares y no, más bien, afirmarían no lugares?

Lo que permiten los flujos es reconfigurar los territorios y, en relación con la estructuración de los lazos sociales, generar un traspaso de lo "social como sociedad" a lo "social como movilidad" (Lash; Urry, 1998). De todos modos, en una primera instancia, podría pensarse que el dominio de los flujos y la conformación de una "sociedad red" o una "ciudad red" (Castells, 2005) acrecentaría las segmentaciones y la fragmentación social. Pero a pesar de la flexibilidad de los vínculos y, por supuesto, la desaparición de las formas tradicionales de solidaridad social, puede pensarse que los espacios son continuamente creados y vivenciados entre los flujos y la continua circulación. Esto es, no asistimos de ninguna manera a otra de las tantas celebraciones de los "fines" de las teorías contemporáneas, a saber, el "fin de los territorios",

\footnotetext{
5. Mongin afirma además que en la condición de lo urbano generalizado, estrictamente, se configuran dos tipos de grandes ciudades: "La tercera mundialización histórica aparece junto con un proceso de borramiento de los límites que, vuelto contra la cultura urbana, repele los límites y no se preocupa por la proximidad. Esta capacidad de alejar los límites da lugar a, esencialmente, dos figuras diferentes, a dos tipos de grandes ciudades: por un lado, la ciudad que es ilimitada en el plano espacial, una ciudad que se extiende más allá de los muros; por otro, la ciudad que se limita para mejorar su relación inmediata con un espacio tiempo mundializado, la ciudad que permanece dentro de sus muros. La ciudad sin límites se despliega hasta el infinito, es la ciudad mundo, la megaciudad; en cambio, la ciudad que se limita, se contrae, se cierra sobre sí misma para sustraerse a sus propios límites, es la ciudad global" (2006, p. 173).
}

6. También se ha hablado y teorizado sobre el surgimiento de una "estética terciaria", cuyas características serían: "retraimiento de la producción cultural, construcción de recorridos dentro de los flujos existentes; producir servicios, itinerarios, en el interior de los protocolos culturales" (Bourriaud, 2007, p. 105). 
al contrario, "las nuevas configuraciones territoriales ponen en escena las metamorfosis del mundo, una de cuyas características es la fluidez" (Mongin, 2006, p. 183). En ese sentido, la ciudad ya no se concibe ni se vive "contra los flujos, sino a partir de los flujos" (p. 192).

La ciudad y el espacio se confirman entonces como una estética en expresión, un devenir inmanente de producciones de la experiencia. En cuanto espacio es normativizante, pero no es de ningún modo trascendental ni representativo. No se define de acuerdo con una exterioridad que se hace presente en el orden de un fundamento. La ciudad es vivida como experiencia en la circulación permanente. Se trata de tránsitos, pasajes en donde se gestan relaciones.

Por esto, coincidimos con Mongin (2006, p. 271) cuando sostiene que: "la condición urbana no se adquiere, es la creación de lugares, la recomposición de lugares". No es que la postmodernidad nos haya soltado hacia los anonimatos de los "no lugares", sino que continuamente hacemos lugares que circulan con nosotros en nuestra propia circulación, y sobre esos lugares vivimos y condensamos vivencias. En otras palabras: "el retorno a los lugares es en sí mismo una experiencia, pues estos no están dados, hay que construirlos" (2006, p. 280).

En cierta manera, estamos diciendo que en la contracción y, simultáneamente, dislocación del espacio en el mundo posmoderno, la movilidad y la circulación no impiden la formación de lazos de sociabilidad, sino que los posibilitan en cuanto continuidad de los flujos. En tales términos, el espacio urbano es concebido como "un lugar practicado", donde se da lugar a "prácticas comunes", pues "quienes generan la ciudad son más las personas que los lugares" (2006, p. 349). Así:

lugar, movilidad y movilización colectiva deben ser coincidentes. La cuestión urbana desemboca, pues, en este triple imperativo: la constitución de un lugar, la exigencia de movilidad a fin de escapar a la clausura de un territorio y la acción colectiva que remite a la participación de los habitantes. (Mongin, 2006, p. 348)

Sin movilidad son imposibles los lugares. La ciudad se convierte, así, en un devenir de todo lo que en ella acontece, de sus pasajes y apropiaciones: "El lugar no lo da todo, no puede bastar para que se desarrolle la acción, para que se dé la vita activa, si no ofrece la ocasión de entablar vínculos con otros lugares, si no hace posible ponerse en movimiento" (Mongin, 2006, p. 351).

La posciudad es el espacio de movilidad que permite hacer y rehacer lugares, transitar entre flujos comprendiendo a cada instante experiencias del lugar y relaciones que nos son dadas entre esos lugares. El espacio deviene una narrativa en transición permanente, un juego de ramificaciones y entrecruzamientos. Y según argumenta Harvey:

En este collage de imágenes espaciales superpuestas que hace implosión sobre nosotros, la identidad de lugar se convierte en un tema importante porque cada persona ocupa un lugar de individuación (un cuerpo, una habitación, una casa, una comunidad que la configura, una individuación), y la forma en que nos individuamos configura la identidad. Más aún, si nadie "conoce su lugar" en este mundo de collages cambiantes. (2008, p. 334)

Lo expuesto nos detalla las experiencias visuales del lugar que hacen posible la congregación de imágenes de lo urbano. Esa dinámica de prácticas, de instancias y experiencias de relación como constitutivas de los lugares, la movilidad y los flujos, las distintas formas de transitar y apropiarse del lugar y de realizarlo como experiencia estética, es lo que despliega el collage a partir del cual se visualizan las narrativas y las imágenes sobre las que definimos la experiencia vivida de los lugares y de las ciudades.

Frente a lo visual, la mirada sobre la ciudad está siempre situada en el flujo de imágenes que la frecuentan. Los objetos, las mercancías, las prácticas de consumo, las redes y telecomunicaciones, los afectos y sensibilidades producen que cada lugar esté en constante transformación y que las miradas no puedan definirlo en un único orden de visualidad, sino que deban proyectarlo en toda la experiencia de su heterogeneidad.

El lugar es un dispositivo estético y una experiencia hermenéutica, porque no representa su imagen o su signo, contrariamente, posibilita la intervención de múltiples interpretaciones que lo desligan de una definición o de la precisión de una verdad. El lugar no tiene centro, es multipolar y se abre a la pluralidad de sus significaciones.

\section{Conclusiones}

Se propuso un análisis de la concepción de lugar como dispositivo estético y también como perspectiva hermenéutica; en este sentido, lo que debe asumirse con claridad y sin reservas es que la cuestión metodológica pertinente se sitúa en la consideración de que el análisis de los lugares y de lo urbano en los tiempos de la globalización y la postmodernidad no puede circunscribir estos a su definición unilateral como simples objetos de estudio. En términos epistemológicos, es necesario decir que lo que se inscribe 
aquí es que el objeto se define en la matriz del propio procedimiento metodológico, en instancias de lo cual, el objeto también inscribe las formas posibles de dicho procedimiento.

Mayor pertinencia muestra esto para un pensamiento de los lugares que no prescinda de sus contextos y de las maneras en que estos son experimentados y practicados por los sujetos. El lugar es una vivencia, y por eso es necesario que sea pensado de acuerdo con las condiciones de su visualidad e imágenes, y en el marco de sus interpretaciones posibles, las cuales pueden articularse con las trayectorias, es decir, con las distintas maneras en que se constituyen a partir de sus recorridos.

La estética de los lugares ya no se inscribe en representaciones dadas, por lo cual el lugar como objeto de análisis no existe, sino que este también es producto de nuestras intervenciones críticas, de nuestra mirada e intervención sobre el mismo, de nuestras formas de descubrirlo y transitarlo, de nuestras maneras de interpretar los sentidos, las apropiaciones y los pasajes mediante los cuales transitamos la imagen de su presencia.

\section{Referencias}

AUGÉ, M. Los no lugares. Espacios del anonimato. Buenos Aires: Gedisa, 2007.

BARTHES, R. Mythologies. Paris: Éditions du Seuil, 1957. BELTing, H. Antropología de la imagen. Buenos Aires: Katz, 2007.

BOURRIAUD, N. Postproducción. Buenos Aires: Adriana Hidalgo, 2007.

CASTELLS, M. La sociedad red. La era de la información: economía, sociedad y cultura, v. 1, Madrid: Alianza, 2005. COMOLLI, J. Ver y poder. Buenos Aires: Aurelia Rivera, 2007.

GARCÍA VÁZQUEZ, C. Ciudad hojaldre. Visiones urbanas del siglo XXI. Barcelona: Gustavo Gili, 2008.
HARVEY, D. La condición de la postmodernidad: investigación sobre los orígenes del cambio cultural. Buenos Aires: Amorrortu, 2008.

JAMESON, F. El giro cultural. Buenos Aires: Manantial, 2002.

LASH, S.; URRY, J. Economías de signo y espacios. Sobre el capitalismo de la posorganización. Buenos Aires: Amorrortu, 1998.

MONGIN, O. La condición urbana. La ciudad a la hora de la mundialización. Buenos Aires: Paidós, 2006.

SARLO, B. La ciudad vista: mercancías y cultura urbana. Buenos Aires: Siglo XXI, 2009.

\section{O lugar como dispositivo estético: fluxos, passagens e percursos da experiência urbana}

\section{Resumo}

O artigo centra-se na análise da categoria lugar em relação com o urbano e suas práticas na pós-modernidade. Assume um critério de análise metodológico sustentado na perspectiva hermenêutica que pretende definir o lugar e o urbano como produção de sentidos e fluxos. Então, o lugar é definido como dispositivo estético e, a partir disso são estabelecidas as dimensões da experiência, das passagens e da visualidade como expressões singulares que definem o lugar sem atribuírem uma representação definida. No primeiro momento, questiona-se a ideia de representação e a definição de lugar segundo seus limites. Em seguida, se propõe o pensamento estético do lugar como expressão. Finalmente, detalha-se o que se compreende como visualidade do lugar. Entre essas relações conceituais evidencia-se uma crítica à categoria de "não lugar" e são considerados os fluxos e trânsitos que permitem pensar os lugares.

Palavras-chave: lugar, espaço urbano, fluxos, passagens, estética. 


\title{
The place as aesthetic device: flows, passages and trajectories of the urban experience
}

\begin{abstract}
The article focuses on analyzing the category of place in relation to the urban and practices in postmodernity. The methodological analysis is defined by a hermeneutic perspective that seeks to define the place and the urban as production of senses and flows. So the place is defined as an aesthetic device, and from there, establishing the dimensions of the experience, the passages and visuality as characteristic expressions that define the place without giving it a definite representation. First, the objective is to review the notion of representation and the definition of the place by its limits. Next, we propose the aesthetic thought of the place as an expression. Finally, it details what is understood as the place visuality. These relationships show a review of the status of "non-place", and consider flows and transits to analyze places.
\end{abstract}

Key words: place, urban space, flows, passages, aesthetics.

Data de recebimento do artigo: 30/01/ 2013

Data de aprovação do artigo: 16/05/2013 